Unionization and certified sickness absence: Norwegian Evidence

Arne Mastekaasa

University of Oslo, Dep. of Sociology and Human Geography

Published in ILRReview, 66(1), 2013 


\section{Unionization and certified sickness absence: Norwegian evidence}

There is a large body of literature on the effects of unions on various employee attitudes and behaviors. Two well-established findings are that union members have lower quit rates, but also lower job satisfaction. In contrast, the relationship between unionization and absence from work (or absenteeism) has not been studied extensively. This is surprising, because the few existing studies indicate large differences in absence rates between members and nonmembers. In early studies of US data sets, Allen (1984) obtained differentials in the 29 to 100 percent range, and similar results were reported by Leigh (1984). Two recent studies of British and Canadian data report differentials between 32 and 40 percent (Tompa, ScottMarshall, and Fang 2011; Veliziotis 2010).

More absence from work among unionized employees is somewhat counterintuitive, as unions might be expected to improve workplace safety and working conditions (Fenn and Ashby 2004; Pencavel 2005). An expectation of lower absence rates among unionized employees can also be grounded in Freeman and Medoff's (1984) development of Hirschman's (1970) exit-voice theory (Garcia-Serrano and Malo 2009).

Although unionization might be expected to reduce employee absence, theory and previous research nevertheless suggest several reasons why this may not be the case. A possible explanation for the unionization-dissatisfaction relationship is that unions make workers more critical and willing to complain (Borjas 1979; Freeman and Medoff 1984). Such a "politicization effect" could also be relevant to absence from work. Another factor that could lead to higher absence among unionized employees is stronger employee protection that may make employees less afraid of management sanctions and more inclined to be absent. More absence from work (or dissatisfaction) among unionized employees could also be because of selection effects, with absence-prone (or dissatisfied) individuals being more likely 
to join (or less likely to leave) a union.

Researchers investigating the unionization-dissatisfaction relationship have made considerable progress in illuminating the underlying causal mechanisms; for instance, by use of panel data (e.g., Heywood, Siebert, and Wei 2002) or linked employer-employee data making it possible to distinguish between individual-level (within firm) differences on the one hand and differences between more or less unionized firms on the other (e.g., Bryson, Cappellari, and Lucifora 2004). This contrasts sharply with the research on unionization and absenteeism, which has relied on cross-sectional models and data on employees only. Thus, the present study, employing linked employer-employee panel data on all individuals employed in Norwegian private sector establishments in the years 2003 to 2007, makes several contributions. First, detailed occupational codes and identification of employees working in the same establishments make it possible to compare union members and nonmembers in identical or at least very similar jobs, thus more or less eliminating the possibility that differences in absence from work are because of differences in working conditions. Second, I can examine whether the unionization-absence relationship arises as a result of differences between individual members and nonmembers, or rather at the establishment level with more unionized establishments having more absence from work than less unionized ones. Possible cross-level interaction effects, i.e., whether the individual-level differential depends on union density (the proportion of the workforce that is unionized), can also be assessed (cf. Bryson, Cappellari, and Lucifora 2004). Third, up to five annual observations for each employee make it possible to control for selection on stable individual characteristics by examining whether change in union membership status is associated with change in absence from work. Finally, as the previous research is limited to Anglo-Saxon countries, a Scandinavian "welfare state" such as Norway should provide an interesting comparative case. 
Previous research has either focused on sickness absence (Tompa, Scott-Marshall, and Fang 2011; Veliziotis 2010) or has also included other types of unscheduled absence (Allen 1984; Leigh 1984). The data analyzed here are confined to sickness absence. As in many previous absenteeism studies (e.g., Markussen, Røed, Røgeberg, and Gaure 2011; Tompa, Scott-Marshall, and Fang 2011; Veliziotis 2010), very short absences_ of less than four days' duration in the present case - are also excluded. Thus, the results below cannot be generalized to these short spells. This is unfortunate because these absences are of interest in their own right. However, they make up only about 13 percent of the total volume of sickness absence in Norway (in terms of days lost). ${ }^{1}$

\section{Theoretical framework and previous research}

\section{Ability and motivation}

In a much-cited article, Steers and Rhodes (1978) argued that absence from work (or its obverse, work attendance) should be seen as a function of both the ability to attend and the motivation to do so. Under the "ability to attend" heading, Steers and Rhodes mention illness and accidents, family responsibilities and transportation problems. There is little doubt that the first of these is the most important, also because illness and accidents are regarded as legitimate reasons for absence, whereas this is not generally the case for family responsibilities and transportation problems.

Some authors (e.g., Garcia-Serrano and Malo 2009) have taken the ability-motivation distinction further and make a distinction between unavoidable absence (determined by ability to attend) and avoidable absence (determined by motivation) as two distinct absence types.

Such a categorization is, however, problematic. An individual may of course be so sick that it

\footnotetext{
${ }^{1}$ According to Statistics Norway, see http://www.ssb.no/english/subjects/06/02/sykefratot_en/.
} 
is completely impossible to attend work, and an employee may stay at home even when perfectly fit. It is likely, however, that these cases are only extremes on a continuum from complete avoidability to complete unavoidability. Very often, absence is probably both health related and avoidable, as when employees decide to stay at home because of headaches, colds or mild psychiatric symptoms. It may be useful to think of an employee as having a sickness threshold; when below this level of sickness he/she goes to work, and when above he/she stays at home (cf. Barmby, Sessions, and Treble 1994). The threshold will depend on motivation, but also on other factors, such as the nature of the work (e.g., how physically demanding it is).

Even physician-certified absence should not by definition be regarded as unavoidable. In the first place, doctors typically have incomplete information and must rely on the patient's own account of his/her symptoms. Second, even with perfect information doctors have incentives to satisfy the patients' wishes, e.g., avoiding unpleasant confrontations or losing patients to other doctors.

\section{Unionization, wages and working conditions}

According to efficiency wage theory, the level of sickness absence can be expected to depend on the wage level: the more the wage exceeds the market wage, the more the employee loses if he/she is dismissed (Barmby et al. 1994). Working conditions may also impact on employee absence. In the first place, problematic working conditions may increase the risk of injury or disease. Second, poor working conditions may make it more difficult for unhealthy employees to attend work and carry out their tasks. Third, poor working conditions are likely to reduce attendance motivation.

The existence of a positive union wage effect is well documented, even in Norway (Barth, Raaum, and Naylor 2000). To the extent that workers care about factors other than 
wages, there are also good reasons to expect unions to contribute to improved workplace safety, reasonable effort demands and pleasant working conditions (cf. Pencavel 2005). An additional reason for expecting better working conditions in unionized workplaces is that good working conditions are to a major extent a collective good that individual workers have little incentive or even opportunity to prioritize (Fenn and Ashby 2004).

However, there is little empirical evidence that unionization is actually associated with better working conditions (Morantz 2009). Studies relating unionization to injury or workrelated illness rates report positive associations as frequently as negative ones (Fenn and Ashby 2004; Robinson and Smallman 2006). The lack of evidence for a favorable union effect on working conditions could be because of methodological problems, such as underreporting of incidents in nonunionized settings (or overreporting in unionized ones). Another possibility is that unions more or less tacitly give priority to wages over working conditions and allow employers to compensate for higher wage costs by intensifying work demands or by spending less on improving working conditions (Bender and Sloane 1998). This might be the case particularly if government regulations impose relatively high standards with regard to health and safety.

\section{Protection effects}

Worker absence has obvious negative consequences for firms, making it more difficult to get the work done, and, if stand-ins are recruited, also leading to higher costs. Thus, employers have an incentive to discourage absence behavior and to lay off workers with high levels of absence. Unions can be expected to protect workers and limit the employer's opportunities to apply negative sanctions against absence behavior, at least as long as the absences are regarded as health related or in other ways legitimate (Balchin and Wooden 1995). 


\section{The exit-voice theory}

According to Freeman and Medoff's (1984) exit-voice theory, dissatisfied employees have two courses of action: either to quit (exit) or to try to obtain improved employment and working conditions (voice). Unions are assumed to strengthen workers' voice, and thus to reduce the probability of exit (i.e., quitting). Several authors have discussed to what extent employee absence can be considered as either exit or voice, and thus the relevance of exitvoice theory for the explanation of union-nonunion differentials in absences (Allen 1984; Garcia-Serrano and Malo 2009; Luchak and Gellatly 1996). A categorization of absence as exit is problematic, because absence represents at best only a temporary exit from a situation regarded as unsatisfactory, and not a real solution to the worker's problem. Absence from work is also problematic as voice, because it would most often produce a very noisy signal, with employers not knowing precisely why the employee is absent (Allen 1984). Whether absence from work serves as exit or voice may, however, not be the crucial issue, because the outcome with regard to the impact of unionization would arguably be the same in both cases. Because unionization provides a voice option, it should reduce absence from work as exit behavior. However, unionization should also provide a voice option superior to that obtained by staying away from work; thus, the union voice should replace the absence-from-work voice (Allen 1984; Garcia-Serrano and Malo 2009; Luchak and Gellatly 1996).

\section{Politicization and attitudes}

The main explanation of the unionization-dissatisfaction relationship suggested by Freeman and Medoff (1984: 138ff.) and Borjas (1979) is that unions have a politicizing effect, making workers more critical and inclined to complain. The politicization effect operates at quite a superficial level: "Note, however, that this dissatisfaction is not genuine in the sense that it leads to quits, but is instead a device through which the union can tell the firm that its workers 
are unhappy and are demanding more" (Borjas 1979: 25). Borjas thus also suggests that unions consciously increase dissatisfaction to achieve their goals.

Consistent with this line of thinking, it has been proposed that unions might use absence from work as a means to demonstrate the seriousness of their dissatisfaction with management. An effect of politicization on absence from work does not, however, presuppose that absence is used as part of a union strategy. If individual workers become more critical of their working conditions, they may become less motivated to go to work, e.g., in the presence of minor diseases or ailments. Unionization might also be associated with the development of more permissive absence norms, or a more permissive local "absence culture" (Drago and Wooden 1992). A negative although not very strong relationship between job satisfaction and absence from work is also well established (see the overview of relevant meta-studies in Johns 2008).

\section{Selection to union membership}

Higher levels of absence among unionized employees could to a greater or lesser extent be because of differential self-selection to union membership. I have already mentioned the possibility of selection related to workplace characteristics, e.g., that poor working conditions may be a motivation for individuals to join a union. However, there could also be selection on individual characteristics. Employees with a high level of absence from work (whether because of health problems or low job motivation) may, e.g., have a greater need for the protection offered by the union and therefore be more likely to be members. Likewise, employees with negative attitudes to management may be more likely to join a union (Bender and Sloane 1998; Clark 1996). 


\section{Institutional context}

Norway has a very generous national system of sick pay, with full wage compensation up to a ceiling well above the mean wage level of full-time employees. Sick pay is paid by the employer for the first 16 days of an absence episode; from day 17 it is tax financed. Certification from a physician is required for episodes of more than three days' duration, and for shorter absences it is sufficient for the employee himself or herself to declare to the employer that the absence is because of sickness (self-certification). The replacement rate for unemployment benefits is 62 percent of previous income. Disability pension is available for those with permanent illness or disability.

The degree of unionization is quite high, and is about 40 percent in the private sector (Løken and Stokke 2009). In general, labor relations are relatively cooperative, both between unions and management and at the national level between unions and employer organizations (Løken and Stokke 2009). Compared with countries such as the US and the UK, employment security is high, with quite strict regulation through law and collective agreements. Sickness (absence) cannot, for example, be used as justification for terminating an employment relationship, although it may still influence termination decisions that can be justified in other ways. High-absence employees may also be punished in various other informal ways, e.g., by not being promoted or by being assigned to less attractive work tasks.

With extensive "worker friendly" institutional arrangements, one might expect Norwegian workers to see little need for joining a union. A recent survey nevertheless found that the opportunity for assistance in the case of "problems in the workplace" was the most frequently cited reason for membership (Nergaard and Svalund 2009). Correspondingly, nonmembers often mentioned a lack of a need for such assistance as a reason for not joining, although, even more frequently, they said that union dues were too high. In general, however, very little research has been carried out on the unionization process in Norway. 


\section{Analytical strategy}

It is the objective of this paper to contribute to our understanding of the causal relationships between unionization and absence from work. The analytical strategy has two main elements. The first is to determine whether the union-nonunion differential in absence from work arises at the individual or the establishment level. The second element is to examine whether absence from work is responsive to changes in membership status or rather a stable individual characteristic. To the extent that the latter is the case, it indicates that the union-nonunion differential is because of selection. I consider these in turn.

An important distinction in the literature regarding union effects is between individual-level and firm- or establishment-level effects, or, in other words, whether union effects primarily produce differences between unionized and nonunionized firms or between union members and nonmembers within the same firm. Working conditions and workplace safety are to a large extent public goods, and union-initiated improvements are enjoyed by both members and nonmembers. Norwegian law also requires that agreements between union and management are applied to nonmembers in the firm (a common feature of industrial relations systems in many European countries as well as the US and Canada) (Løken and Stokke 2009). This also applies to wages; unionized firms pay higher wages, but there is no within-firm union membership effect (Barth et al. 2000).

The situation is likely to be different when it comes to the union's role in assisting individual workers in their relations with management (e.g., providing legal advice when management wants to dismiss a high-absence worker), because unions are unlikely to extend such services to nonmembers. ${ }^{2}$ Politicization effects are also likely to operate within firms,

\footnotetext{
${ }^{2}$ One of the referees noted that, in the US, union stewards must represent all employees
} 
creating differences between union members and nonmembers (and one would also expect politicization to influence whether an employee decides to join a union or not). Self-selection to union membership is of course by definition assumed to operate at the individual level.

Union effects on absence from work may also come about as a result of a combination of individual-level and establishment-level processes. The ability of a union to provide effective protection to individual employees is, e.g., likely to be stronger the higher the union density, thus creating larger differentials between members and nonmembers under high union density. Stronger unions should also be better able to improve working conditions, but as argued above, this is likely to benefit both members and nonmembers (Borjas 1979; Bryson, Cappellari, and Lucifora 2004). Politicization effects could be different in weakly and strongly unionized firms, but it is not obvious how. On the one hand, strong unions may be expected to have the strongest impact on their members. However, the politicization effect could also be strongest when unions are weak and not able to obtain satisfactory results for their members. In line with this idea, Bryson, Cappellari, and Lucifora (2010) find that union membership leads to lower job satisfaction only in occupations not covered by collective bargaining agreements.

The second element in the analytical strategy is to utilize the longitudinal data to differentiate between variation within and between individuals. If a higher level of absence among union members is a result of selection to membership based on relatively stable individual characteristics (such as, e.g., health and motivation), it should be visible even before the employee joins a union and after he/she terminates his/her union membership. A causal effect of membership, on the other hand, implies that the level of absence changes when membership status changes. A problem here is that a potential effect may not be

whether they are union members or not. This is not the case in Norway. 
immediate, but may involve time lags. I therefore also estimate models showing the level of sickness for the up to four years preceding and up to the four years succeeding the change in membership status.

The early research by Allen (1981) and Leigh (1984) suggested that union effects on absence may be stronger for blue collar than for white collar workers. I thus perform separate analyses for employees in jobs typically requiring at least some higher education on the one hand and in occupations requiring at most secondary education on the other.

\section{Methods}

Data

The analyses are based on Norwegian public register data that cover the entire employed population (apart from the self-employed). All employment relationships active on May 15 in a particular year are included. I exclude persons below 18 or above 60 years of age. The analyses are limited to the years 2003 to 2007 and to the private sector, primarily because information on occupation is not available for earlier years or for the public sector. Information on occupation is also missing for seven percent of the private sector observations, and these are also excluded.

The data are limited to sickness absence episodes certified by a physician (i.e., of more than three days' duration). All such absences are reported to the Norwegian Labour and Welfare Administration. This agency also administers a mandatory public pension scheme and therefore keeps records of all employment relationships. This register also contains an identification number for each establishment, making it possible to link employers and employees. Supplementary information on education is taken from population registers available at Statistics Norway. Information from the various registers was merged by Statistics Norway using unique personal identification numbers, which were removed from 
the data before they were made available for research.

I mainly use a binary indicator of annual absence from work, distinguishing between at least one new episode during a year and no episode. ${ }^{3}$ Supplementary analyses are carried out for the total number of absence days during the year and for absence frequency (the number of absence episodes initiated during the year). Absence days will primarily be sensitive to long absence episodes, whereas absence frequency will be more sensitive to short spells (Darr and Johns 2008). For further sensitivity checks, I also employ dichotomized versions of these variables: more than 28 absence days versus 28 days or less, and two or more absence episodes versus less than two episodes, respectively.

Information on union membership is taken from income tax returns. Union membership is visible on these because membership fees are deductible. ${ }^{4}$ In some analyses, the timing of changes in membership status is taken into account by including a dummy variable for each single year preceding the change and for each year succeeding it, with the year immediately preceding the change as the omitted category.

Union density is the proportion of all employees in the establishment that are union members. In the regressions, union density is entered as five splines (for 0 to $.2, .2$ to .4 , etc.) to capture possible nonlinearities.

Occupation is coded using detailed seven-digit codes. The coding scheme consists of the most detailed ISCO codes (four digits) plus three more digits that add even more detail.

\footnotetext{
${ }^{3}$ The restriction to new absence episodes means that an episode is not counted more than once if it lasts from one calendar year to the next.

${ }^{4}$ There is no direct evidence on the validity or reliability of this measure. Aggregated over the entire economy it does, however, provide very similar estimates to those of nationwide survey data, viz. 51 versus 53 percent union members in 2008 (Nergaard and Stokke 2010).
} 
Industry is coded in terms of four-digit NACE codes. Following Allen (1981) and Leigh (1984), I perform separate analyses for employees in occupations typically requiring higher education on the one hand and other occupations on the other. The former ("higher grade") category is defined by first-digit ISCO codes 1 to 3 and the latter ("lower grade") by codes 4 to 9 .

Age (in years) and number of days employed during the year are treated as continuous variables, with second- and third-order terms included when necessary to take nonlinearities into account. Working hours per week is a categorical variable distinguishing between less than 20 hours, 20 to 30 hours, and more than 30 hours, with the latter as reference. Level of education has seven categories ranging from lower secondary or below (lower secondary is compulsory) to the $\mathrm{PhD}$ level. Tenure with the employer is given in three categories: less than a year, between one and five years, and more than five years. See Table 1 for details.

\section{Statistical methods}

Fixed effects (FE) models are the central statistical tool in the analyses. With FE estimation only variations within given groups (which may be defined in various ways) are used to estimate the parameters. The linear FE model is as follows:

$A B S E N C E_{i t}=\alpha+\beta U N I O N_{i t}+X_{i t}^{\prime} \boldsymbol{\gamma}+\pi_{i}+\varepsilon_{i t}$,

where the subscript $i$ refers to the group level and $t$ to the individual observation within the group, $\boldsymbol{X}$ is a vector of control variables, $\pi_{i}$ are the fixed effects, $\alpha$ and $\beta$ and are regression parameters, $\boldsymbol{\gamma}$ is a vector of parameters, and $\varepsilon_{i j}$ are the error terms associated with each observation. With FE estimation, the $\pi_{i}$ are eliminated by deviating all variables from their group means.

The first part of the analyses examines to what extent the union-nonunion differential arises at the establishment or the individual level. I estimate an FE model with groups defined 
by the combination of establishment and occupation codes. This means that the estimated union membership effects will be based on within-establishment (and within-occupation) variation only, and be unaffected by heterogeneity between establishments (e.g., better or worse working conditions in unionized than in nonunionized workplaces). The withinestablishment estimates are compared with a baseline FE model, with the groups defined by the combination of industry and occupation codes, thus eliminating variation between industries and occupations (but not establishments).

The second objective is to assess union density effects. The model with groups defined by industry plus occupation is augmented by a set of spline variables for the proportion of the workers in the establishment who are unionized and the interaction of these splines with union membership:

$A B S E N C E_{i t}=\alpha+\beta U N I O N_{i t}+\boldsymbol{X}_{i t}^{\prime} \boldsymbol{\gamma}+\boldsymbol{D}_{i t}^{\prime} \boldsymbol{\delta}+(U N I O N \times \boldsymbol{D})_{i t}^{\prime} \boldsymbol{\vartheta}+\pi_{i}+\varepsilon_{i t}$,

where $\boldsymbol{D}$ is the vector union density splines, $\boldsymbol{\delta}$ and $\boldsymbol{\vartheta}$ are vectors of regression parameters and the other terms are as defined above. This model implies that workers are compared across establishments but still within industries and occupations.

The third part of the analyses assesses the importance of self-selection to union membership. This analysis exploits the panel properties of the data with up to five annual observations per individual. Using eq. (1) and grouping even by individuals, union membership effects can be estimated on variation within individuals only, thus eliminating between-individual heterogeneity, e.g., stable individual differences in health. Note that in these analyses, the grouping (defined by $\pi_{i}$ ) is by both industry, occupation, and individual; thus, possible confounding of the effects of membership changes with the effects of changes in industrial and occupational characteristics is eliminated.

To the extent that the union-nonunion differential is not entirely caused by selection on stable individual characteristics, it is useful to examine in more detail what actually 
happens with regard to sickness absence in the years immediately preceding and following membership changes. To address this issue I constructed a reduced data set (a so-called balanced panel) containing only those individuals who were observed each year from 2003 to 2007, and who had at most one membership change. I then estimated the same type of model as above (i.e., Eq. (1) with the fixed effects defined by both industry, occupation, and individual), except for replacing the union membership dummy with a dummy variable for each year before and after the change, using the last year before the change of membership as the reference category:

$A_{B S E N C E_{i t}}=\alpha+\sum_{j=-4}^{+3} \varphi_{j} I N_{i t-j}+\sum_{j=-3}^{+4} \omega_{j} O U T_{i t-j}+\boldsymbol{X}_{i t}^{\prime} \boldsymbol{\gamma}+\pi_{i}+\varepsilon_{i t}$,

where the $I N_{t-j}$ are dummy variables for the years preceding $(j=-4$ to -1$)$ entry into union membership, the year of entry $(j=0)$, and the years succeeding $(j=1$ to 3$)$ entry, and $\varphi_{j}$ are the corresponding coefficients. The year before entry is used as the omitted category; i.e., $\varphi_{-1}$ is set to zero. Likewise, the $O U T_{t+j}$ are dummy variables for the years preceding and succeeding termination of union membership, with corresponding coefficients $\omega_{j}$, and with $\omega_{-1}$ set to zero. ${ }^{5}$ As in the previous analysis, the grouping (defined by $\pi_{i}$ ) is by both industry, occupation, and individual.

The reliance on FE methods has some implications for other methodological choices. FE works well within an OLS context. FE methods for a number of other regression models have been developed (Wooldridge 2002: Ch. 15.8 and 19.6.4). A major limitation of these non-OLS FE models, however, is that only groups with variation in the dependent variable can be included. When using fixed individual effects, e.g., this means that employees with no absence episodes during the period of observation will be excluded.

\footnotetext{
${ }^{5}$ For similar approaches to the modeling of "anticipation" and "adaptation" effects, see
} Frijters, Johnston, and Shields (2011) or Powdthavee (2011). 
Because of this problem, I rely mainly on OLS models and a binary absence variable. This linear probability model generally works well, at least for estimating average marginal effects, which is the central concern in this study (Wooldridge 2002: 455). Robust standard errors are used.

Although I mainly rely on OLS, some additional analyses using Poisson regression on the number of absence days and on the number of absence episodes are included to assess the robustness of the results. The distributions of these variables deviate considerably from the Poisson distribution, but with regard to the estimation of the expected count and the impact of explanatory variables on this count, Poisson regression parameter estimates are known to be consistent (Wooldridge 2002: 648ff.). Robust standard errors taking into account clustering of individuals within establishments are employed.

To compare results across models, average marginal means for union members and nonmembers are often computed. With a binary dependent variable, the mean can be interpreted as a probability, and the ratio of the average marginal absence probability for members to that of nonmembers is the relative risk (RR) of absence. In Poisson regression, the ratio of the average marginal means can likewise be interpreted as an incidence rate ratio (IRR).

[Tables 1 and 2 about here]

\section{Results}

\section{Descriptive statistics}

Table 1 provides descriptive statistics for three categories of individuals: those who are nonmembers for all years in which they are observed, those who are members in all years, and those with varying membership status. Union members have the highest number of absence 
days and absence episodes and the highest probabilities of having at least one absence episode, two or more episodes, and more than 28 absence days during the year. Stable nonmembers have the lowest mean scores on all these measures, and individuals with varying membership status are intermediate between these. ${ }^{6}$ Stable members are also the category with the highest mean number of employees in the establishment, and the highest proportions with full-time work and with long tenure with the employer. The stable member category also tends to have the highest average age and the highest proportion of men; the age and gender differences are small, however. The bottom line in Table 1 shows that the average number of years each employee is present in the data varies from 3.1 to 3.8 (the maximum is five for those present for all years from 2003 to 2007). (Note that these numbers do not show the average of the number of years employed, because only years in private sector employment are included.) ${ }^{7}$

Since the numbers in Table 1 are averaged over all years, Table 2 provides summary information on variations over the observation period. The proportion with at least some sickness absence in all five years of observation is quite small, whereas up to 40 percent are not absent at all during this period. ${ }^{8}$ Clear differences between stable non-members on the one hand and stable members and individuals with varying membership status on the other are found both in the bottom (i.e., with regard to having no absence at all) and in the top (i.e.,

\footnotetext{
${ }^{6}$ The union-nonunion differential is quite similar in the public and private sectors in Norway. For current members, the proportion with at least one absence episode during the year is .34 in the private sector and .31 in the public sector (2003 to 2007 average). For nonmembers, these proportions are .25 and .22 , respectively.

${ }^{7}$ The differences in sickness absence between the three groups are similar irrespective of whether all employees or only employees observed in all five years (i.e., a so-called balanced panel) are used. Details are available upon request.
}

${ }^{8}$ The results are largely the same if only individuals observed in all five years are included. 
with regard to having at least one absence spell each year) of the distribution.

\section{The union-nonunion differential}

Table 3 presents two FE models separately for higher- and lower-grade employees. In Model 1, the fixed effects are defined in terms of a cross-classification of industry and occupation; it thus removes heterogeneity between industries and occupations, but still employs variation both within and between establishments. Model 2 includes fixed effects for establishmentoccupation combinations, and only variation among employees sharing both occupational category and employer is used in the estimation.

As a linear probability model is used, the coefficients can be interpreted directly in probability terms. For higher-grade employees, the probability of sickness absence is .024 higher for members than for nonmembers. The average marginal probabilities for the two categories on the membership variable are .236 and .212 , respectively (not shown in the table). The coefficient for union membership thus corresponds to an 11 percent higher probability for union members (given identical values on the control variables and identical industry and occupation codes). Limiting the estimation to variation within establishment-occupation combinations (Model 2) leads to a decrease in the estimated union effect to .017, or eight percent. Thus, overrepresentation of union members in high-absence establishments within given industries is of some importance, but about 70 percent of the union-nonunion differential arises within establishments.

Turning now to lower-grade occupations, the union-nonunion differential tends to be two to three times larger than for higher-grade employees. Under Model 1, the average marginal probability is .363 for members and .292 for nonmembers, a difference of 24 percent. The impact of introducing fixed establishment effects, however, is similar to what was found for higher-grade employees: a small reduction in the estimated differential from .071 to .057 
(or from 24 to 19 in percentage terms).

For the sake of brevity, I will not comment in detail on the other results in Table 2. It may be noted, however, that even within occupational categories, sickness absence declines strongly with the level of education. Even more striking are the large gender differences. Sickness absence increases with age until employees are in their early 30 s, then declines, but increases somewhat again among the oldest employees in our sample (approaching 60 years of age). ${ }^{9}$ Sickness absence is also somewhat lower among part-time employees and, except for very recently employed individuals, who have quite low absence, it declines with tenure. Sickness absence increases with establishment size until a level of about 800 employees for lower-grade employees and 1400 for higher-grade employees, and declines thereafter. The relationship is quite weak, however.

[Table 3 about here]

Two $\mathrm{R}^{2}$ values are given for each model in Table 3 . The first one provides the proportion of variance accounted for by the explanatory variables after having removed the fixed effects (i.e., explained within groups variation), and the second one includes the fixed effects (i.e., treats these as ordinary explanatory variables). The within values in particular are generally low. This may seem surprising given the strong effects of some of the explanatory variables, in particular gender and education. In part this reflects that $\mathrm{R}^{2}$ is a problematic measure with dichotomized variables, as dichotomization leads to considerable attenuation of correlations, and the more so the more skewed the dichotomized variable is (see, e.g., Cohen 1983). In addition, removal of systematic variation due to the fixed effects necessarily leads to an increase in the proportion of random variation. However, even when including the fixed

\footnotetext{
${ }^{9}$ Age differences in sickness absence in Norway are discussed in Markussen, Røed, Røgeberg, and Gaure (2011).
} 
effects (and taking into account the large number of these), the $\mathrm{R}^{2}$ values are not impressive, indicating that sickness absence are only to a quite limited extent due to job and workplace characteristics.

A number of analyses were carried out to assess how sensitive the findings are with regard to the exclusion of observations with missing data on occupation, the choice of statistical model, and the measurement of sickness absence. Excluding the seven percent of the observations with missing data on occupation appears to have minimal impact. A modified version of Model 1 in Table 2 with fixed effects for industry only and estimated for all observations yielded a coefficient for union membership of .077; when excluding observations with missing data, the coefficient was .076 .

[Table 4 about here]

Table 4 presents the main results from alternative regression models and operationalizations (full results are available upon request). For lower-grade occupations, rate ratios (IRR) estimated by Poisson regression are very similar to relative risks (RR) based on the OLS estimates in Table 3, although there is some tendency for the estimates to be highest for the number of episodes and lowest for days lost, with the OLS estimates in between. This pattern is more pronounced for lower-grade occupations. Thus, union membership tends to be somewhat more strongly related to the number of episodes (which is relatively more sensitive to short-term absences) than to the number of days lost (which is more sensitive to long-term absences).

This impression is substantiated in the additional OLS regressions in Table 4, employing different operationalizations of sickness absences. Thus, the highest risk ratios are found when the dependent variable distinguishes between those with relatively frequent absence episodes (two or more) and the rest. Distinguishing instead between those with relatively many days lost (more than 28 days) and the rest, on the other hand, has little impact 
on the results.

Apart from the somewhat stronger union membership estimates for absence frequency than for absence days or the incidence of any sickness absence, the main findings are consistent across models and operationalizations. Thus, the relationship between union membership and sickness absence is considerably stronger in lower-grade than in highergrade occupations, and this is primarily because of differences between members and nonmembers within establishments, and not because of between-establishment variation.

\section{Union density}

So far, the analyses have established that the overall difference in absence among unionized and nonunionized employees largely reflects individual-level, within-establishment processes. I now turn to possible variations in this within-establishment differential, more specifically, to whether it is related to union density. This is addressed by augmenting Model 1 in Table 3 with the union density splines and interactions of these splines with the union membership dummy. Average marginal probabilities are given in Figure 1. A table with coefficients, etc., is available upon request.

[Figure 1 about here]

F-tests of the five union density splines and of the five interactions of these with the membership dummy lead to rejection at the .001 level of the null hypotheses that all 10 coefficients are zero (for higher-grade employees $\mathrm{F}$ is 14.50 , and for lower-grade employees 72.03). Given the large sample size, these tests are not very informative, however, because even relationships of quite trivial magnitude will be significant. Figure 1 shows that the relationship between union density and sickness absence is very weak, and this applies to both members and nonmembers, and to both higher-grade and lower-grade employees. 


\section{Selection effects and changes over time}

The union-nonunion differential could reflect not only a causal effect of union membership, but also a selection of high-absence employees into union membership. An effective control for selection on stable individual characteristics is to estimate membership effects using within-employee variation only, i.e., with fixed individual effects. In Table 5, the main results from these analyses are given as Model 2. For comparison, I also present Model 1 without individual fixed effects. To save space, only relative risks are presented; detailed results are available upon request.

[Table 5 about here]

Considering Model 1 first, the relative risks are very similar to those previously reported for Model 1 in Table 3. This is as expected because this is essentially the same model; it is nevertheless included here for comparison and because the sample I now analyze excludes individuals with only a single annual observation.

With absence versus no absence as the dependent variable, the estimated membershipnonmembership differential is reduced by about half in Model 2 in the lower-grade occupations (because an RR of 1.249 implies that sickness absence is 24.9 percent more common among members than among nonmembers, and 1.123 likewise translates into 12.3 percent). Thus, up to half of the total differential between otherwise similar employees seems to be because of selection of absence-prone individuals to union membership. For highergrade employees, the decline in the estimated union effect from Model 1 to Model 2 is smaller, but still substantial in relative terms (with RR declining from 1.120 to 1.076), so selection appears to be of some importance even here.

The results from the analyses of having two or more versus less than two episodes also provide evidence that selection to union membership may account for about half of the unionnonunion differential among lower-grade employees and somewhat less among higher-grade 
employees. As far as long-term absence (more than 28 days lost during the year) is concerned, however, the estimated union differential changes little or nothing from Model 1 to Model 2, so here selection can explain very little.

[Figures 2 and 3 about here]

Although selection to union membership is important, particularly for lower-grade employees, a true membership effect seems to remain. Using Equation (3), I therefore examine in more detail how sickness absence develops in the years immediately preceding and succeeding change of membership status. For the sake of brevity, full results are not presented (but they are available upon request). ${ }^{10}$ Figures 2 and 3 present the estimated coefficients for the years before and after the change (the $\varphi_{j}$ and $\omega_{j}$ coefficients). Estimates are given based on separate analyses for lower and higher grade employees and on a pooled analysis of both groups. The pooled analysis was added since the results for the two groups are very similar, and to reduce the otherwise rather high standard errors. For the estimates from the pooled analysis, 95 percent confidence intervals are also given.

Figure 2 shows that termination of union membership is associated with a clear and significant drop in sickness absence for both lower and higher grade employees. However, the drop seems to be only temporary. Figure 3 shows that employees entering a union exhibit a considerable increase in sickness absence. This increase is not concentrated to the year of entry, however, but occurs over several years both before and after entry. The increase seems to level off two to three years after entry, but only among lower grade employees.

\section{Discussion}

\footnotetext{
${ }^{10}$ Additional descriptive statistics on the proportion with absence before and after a change in membership status are also available upon request.
} 
This study has shown that unionized employees in Norway are considerably more absent from work than are their nonunionized counterparts. This is the case even when comparing people with the same detailed occupation and industry codes, who should therefore be in very similar if not identical jobs. Depending upon the choice of absence measure, the differential varies between nine and 20 percent for higher-grade employees and between 20 and 47 percent for lower-grade employees. Overall, these estimates are lower than the results reported in previous studies from the US, Canada and the UK, but not by a very large margin, at least not with regard to comparisons with the two latter countries (Allen 1984; Leigh 1984; Tompa, Scott-Marshall, and Fang 2011; Veliziotis 2010). Furthermore, the fixed occupation-industry effects employed here probably remove considerably more heterogeneity than the control variables used in the previous studies. Indeed, if the OLS Model 1 for at least one episode in Table 3 is estimated without FE but instead with control for first-digit ISCO code only, then the estimated union-nonunion differential increases from 11 to 17 percent for higher-grade and from 24 to 31 for lower-grade employees (results available on request). Thus, the unionnonunion differentials do not seem to be very different in Norway compared with these other countries - despite large differences in institutional context.

With regard to the incidence of any sickness absence during the year, the findings suggest that up to half of the total union-nonunion differential is because of selection of absence-prone employees to union membership. As far as long-term absence (more than 28 days per year) is concerned, however, such selection effects do not seem to be important. I do not know of any previous research that has examined selection specifically with regard to union-nonunion differentials in absence from work. The selection issue has, however, been addressed in the unionization and job satisfaction literature, and several studies have been carried out using either panel data or instrumental variable techniques. No clear pattern has emerged, however. Bender and Sloane (1998) and Bryson, Cappelli, and Lucifora (2004) both 
report evidence that the lower job satisfaction among union members is largely because of a negative selection to union membership. Heywood, Siebert, and Wei (2002), however, conclude that the job satisfaction differential cannot be accounted for by selection effects, and Bryson, Cappelli, and Lucifora (2010) found that there was a negative selection to membership for employees covered by collective contracts, but a positive selection for employees who were not covered.

Although this study provides strong evidence of the overall importance of selection effects, it does not provide any direct information about the specific processes by which the selection to membership status occurs. The selection could be on health or health-related characteristics, as poor health may lead to a greater need for union protection and for other services a union can offer. The finding that selection to membership status cannot explain union-nonunion differences in long-term absence goes against this interpretation, however, because one would expect these absences to be the ones most strongly related to health. Another possibility is that the selection is of a more motivational and attitudinal kind, as one would expect if similar selection processes accounted for the union-nonunion differentials in both absence from work and job satisfaction. Very ambitious and career-oriented individuals may, for instance, both be less interested in joining a union and more inclined to go to work in the presence of minor health problems. Personality factors could also influence both union membership and absence behavior.

The union effect on absence from work is a union membership effect and not an effect of working in a unionized establishment. This finding is inconsistent with the assumption that the relationship between unionization and work absence is because of differences in working conditions, as there is little reason to believe that members have less satisfactory working conditions than nonmembers in the same detailed job category. Such unfavorable treatment of union members would be particularly unlikely when union density (and presumably union 
power) is high; as we have seen, however, there is no indication that the union-nonunion absence differential is smaller in high-density establishments.

Given that establishment-level factors do not seem to contribute to the unionnonunion differential in absence from work, the question becomes: What individual-level factors are likely to be operating? Above, I discussed three candidates: the exit-voice theory, protection effects and politicization or attitudes.

The most reasonable derivation from exit-voice theory is lower absence among unionized employees. The present study is consistent with previous studies of unionization and work absence in not finding any support for this. Does the cumulative evidence mean that we can conclude that exit-voice theory is irrelevant to the explanation of absence from work? Not necessarily. Garcia-Serrano and Malo (2009) have argued that tests of exit-voice theory need to distinguish between voluntary and involuntary absence, as union voice should reduce the former but not the latter. With regard to involuntary absence, they argue that unions should rather have a positive effect, because of the protection effect discussed above (which Garcia-Serrano and Malo discuss in terms of reduced "presenteeism"). I have argued above that an attempt to categorize absence as either voluntary (i.e., because of motivation) or involuntary (because of a lack of ability to go to work) is likely to be futile, as most cases of absence will be a joint function of both. Nevertheless, one might suggest that union-nonunion differences in absence from work are a result of two opposing processes: a voice effect and a protection effect. Higher levels of absence among union members than among nonmembers would then reflect that the protection effect is stronger than the union voice effect, and the results obtained in this study might be because of the omission of absences not certified by a physician. This interpretation is not particularly likely, however, as the present findings are well in line with previous research using broader absence definitions.

With the data at hand, it is not possible to distinguish between union protection effects 
and union effects on employee attitudes (politicization). It may be relevant to note, however, that the difference in absence between union members and nonmembers is only weakly related to union density and that members are not more often absent when union density is high. It would seem reasonable to expect numerically strong unions to have more impact on attitudes than weaker unions have. This is particularly so to the extent that absence attitudes are developed through local interaction in the workplace, as is assumed in theories of socalled absence cultures (Nicholson and Johns 1985).

The analyses of changes in union membership showed that termination of membership is associated with an instantaneous drop in sickness absence. This is as expected if membership has a causal effect. Such an effect seems to be short-lived, however. Thus, it cannot explain much of the overall union-non-union differential in sickness absence.

The pattern of change over time is very different for employees who join a union. In this case there is a gradual increase in sickness absence both before and after joining, and no abrupt change. Such a pattern of gradual increase is consistent with a hypothesis of selection on temporary factors. In the analyses above, selection to union membership based on stable individual characteristics was controlled for by the inclusion of individual fixed effects, but it is still possible that changes in health or in motivation lead to changes both in union membership status and in absence behavior. A gradual deterioration in health, for instance, may increase the level of absence, and thus also the value of union membership as a protective device.

Although union members are more absent than nonmembers even among higher-grade employees, the difference is much larger among lower-grade employees. This is in line with early US studies by Allen (1981) and Leigh (1984). There are several reasons to expect such a difference. For one thing, higher-grade employees are probably in a stronger position vis à vis management and have less need for union protection than do lower-grade employees. 
Moreover, although organizations for higher-grade employees are unions in the sense that they may bargain with management and represent individual members vis à vis management, they typically also take care of members' professional interests (as engineers, accountants, psychologists, etc.). This does not necessarily imply that unions representing such employees behave differently in relations with management, but employees are likely to be attracted to these unions even for reasons other than those traditionally associated with unionization. Thus, the selection to union membership may be different among lower- and higher-grade employees.

The data analyzed in this article have been limited to absence episodes certified by a physician. Short absence episodes (of three days' duration or less) declared by the employee to be because of sickness are not included. Thus, the findings here cannot be generalized to these absences. I have also excluded public sector employees.

\section{Conclusion}

This study has established some important facts about the relationship between unionization and absence from work. In the first place, the union-nonunion differential is largely produced at the level of the individual employee. Heterogeneity between establishments (or, by implication, firms) and even between job categories or detailed occupations is of little importance in explaining the union-nonunion differential. I have also shown that individuallevel selection of absence-prone individuals to union membership is important and accounts for up to 50 percent of the total difference in absence between union members and nonmembers.

I cannot draw definitive conclusions with regard to the causal processes underlying the remaining union-nonunion differential in absence, not even with regard to the direction of causality. An abrupt drop in sickness absence in the year of departure from the union is 
exactly what one would expect if union membership has a true causal effect, but then any such effect seems to be only transitory. The gradual increase in sickness absence in the years before and after entering a union, on the other hand, suggest that we are here seeing a more long term change in health or in work motivation, and that the act of joining a union is part of this process, i.e., a result of selection on temporary characteristics.

Major strengths of this study were data allowing for the separation of within- and between-establishment effects, and also longitudinal information making it possible to determine to what extent the union-nonunion differential is because of selection to membership status on stable individual characteristics. This type of register data nevertheless has obvious limitations, such as a lack of information on workers' motivations - for work attendance as well as for joining or leaving a union. Further research using other data is also necessary to determine to what extent the findings can be generalized to very short absence spells.

Labor market institutions and other contextual factors vary considerably among countries. Accumulation of findings from different countries is therefore important to assess the limits of generalization and to examine to what extent different patterns arise in different institutional contexts. Against the background of previous research on the US, the UK, and Canada, Norway provides an interesting comparative case with, e.g., much more extensive social welfare provisions, a much higher degree of unionization, and lower earnings inequality. Despite these large differences, the overall size of the union-nonunion differential in sickness absence does not seem to be dramatically different in Norway than in these countries. Only future research can show to what extent even the more specific findings reported in this paper, e.g. the great importance of selection effects, can be replicated for other countries. 


\section{References}

Allen, Steven G. 1981. An empirical model of work attendance. The Review of Economics and Statistics, 63 (1): 77-87.

Allen, Steven G. 1984. Trade unions, absenteeism and Exit-Voice. Industrial and Labor Relations Review, 37 (3): 331-345.

Balchin, Jeffrey, and Mark Wooden. 1995. Absence penalties and work attendance. Australian Economic Review, 28 (4): 43-58.

Barmby, Tim, John Sessions, and John Treble. 1994. Absenteeism, efficiency wages and shirking, Scandinavian Journal of Economics, 96 (4): 561-566.

Barth, Erling, Oddbjorn Raaum, and Robin Naylor. 2000. Union wage effects: Does membership matter? The Manchester School, 68 (3): 259-275.

Bender, Keith A., and Peter J. Sloane. 1998. Job satisfaction, trade unions and exit-voice revisited. Industrial and Labor Relations Review, 51 (2): 222-240.

Borjas, George J. 1979. Job satisfaction, wages and unions. Journal of Human Resources, 4 (1): $21-40$.

Bryson, Alex, Lorenzo Cappellari, and Claudio Lucifora. 2004. Does union membership really reduce job satisfaction? British Journal of Industrial Relations, 42 (3): 439-459.

Bryson, Alex, Lorenzo Cappellari, and Claudio Lucifora. 2010. Why so unhappy? The effects of unionization on job satisfaction. Oxford Bulletin of Economics and Statistics, 72 (3): $357-380$.

Clark, Andrew E. 1996. Job satisfaction in Britain. British Journal of Industrial Relations, 34 (2): 189-217.

Cohen, Jacob. 1983. The cost of dichotomization. Applied Psychological Measurement, 7 (3): 249-253.

Darr, Wendy, and Gary Johns. 2008. Work strain, health, and absenteeism: A meta-analysis. 
Journal of Occupational Health Psychology, 13 (4): 293-318.

Drago, Robert, and Mark Wooden. 1992. The determinants of labor absence: Economic factors and workgroup norms across countries. Industrial and Labor Relations Review, 45 (4): 764-778.

Fenn, Paul, and Simon Ashby. 2004. Workplace risk, establishment size and union density. British Journal of Industrial Relations, 42 (3): 461-480.

Freeman, Richard B., and James L. Medoff. 1984. What Do Unions Do? New York: Basic Books.

Frijters, Paul, David W. Johnston, and Michael A. Shields. 2011. Life satisfaction dynamics with quarterly life event data. Scandinavian Journal of Economics, 113 (1): 190-211.

Garcia-Serrano, Carlos, and Miguel A. Malo. 2009. The impact of union direct voice on voluntary and involuntary absence. Journal of Socio-Economics, 38 (2): 372-383.

Heywood, John S., Stanley Siebert, and Xiangdong Wei. 2002. Worker sorting and job satisfaction: The case of union and government jobs. Industrial and Labor Relations Review, 55 (4): 595-609.

Hirschman, Albert O. 1970. Exit, Voice and Loyalty. Cambridge, MA: Harvard University Press.

Johns, Gary. 2008. Absenteeism and presenteeism: Not at work or not working well. In Julian Barling and Cary L. Cooper (Eds.), The Sage Handbook of Organizational Behavior, Vol. 1, pp. 160-177. London: Sage.

Leigh, J. Paul. 1984. Unionization and absenteeism. Applied Economics, 16 (2):147-157.

Løken, Espen, and Torgeir A. Stokke. 2009. Labour relations in Norway. Report 2009:33. Oslo: Fafo.

Luchak, Andrew A., and Ian R. Gellatly, 1996, Exit-Voice and employee absenteeism: A critique of the industrial relations literature. Employee Responsibilities and Rights 
Journal, 9 (2): 91-102.

Markussen, Simen, Knut Røed, Ole J. Røgeberg, and Simen Gaure. 2011. The anatomy of absenteeism. Journal of Health Economics, 30 (2): 277-292.

Morantz, Alison. 2009. The elusive union safety effect: Toward a new empirical research agenda. In Adrienne E. Eaton (Ed.), Proceedings of the 61st Annual Meeting (San Francisco, January 3-5, 2009), pp. 130-146. Urbana-Champaign, IL: Labor and Employment Relations Association.

Nergaard, Kristine, and Torgeir Aakvaag Stokke. 2010. Arbeidslivets organisasjoner 2008/2009. Report 2010:47. Oslo: Fafo.

Nergaard, Kristine, and Jørgen Svalund. 2009. Fagorganisering blant arbeidstakere med høy utdanning. Report 2009:22. Oslo: Fafo.

Nicholson, Nigel, and Gary Johns. 1985. The absence culture and the psychological contract who's in control of absence? The Academy of Management Review, 10 (3): 397-407.

Pencavel, John. 2005. Unionism viewed internationally. Journal of Labor Research, XXVI (1): 65-97.

Powdthavee, Nattavudh. 2011. Anticipation, free-rider problems, and adaptation to trade unions: Re-examining the curious case of dissatisfied union members. Industrial and Labor Relations Review, 64 (5): 1000-1019.

Robinson, Andrew M, and Clive Smallman. 2006. The contemporary British workplace: A safer and healthier place? Work, Employment and Society, 20 (1): 87-107.

Steers, Richard M., and Susan R. Rhodes. 1978. Major influences on employee attendance: A process model. Journal of Applied Psychology, 63 (4): 391-407.

Tompa, Emile, Heather Scott-Marshall, and Miao Fang. 2011. Social protection and the employment contract: The impact on work absence. Work, 37 (3): 251-260.

Veliziotis, Michail. 2010. Unionization and sickness absence from work in the UK. Working 
Paper 2010-15. Institute for Social and Economic Research, University of Essex.

Wooldridge, Jeffrey. 2002. Econometric Analysis of Cross Section and Panel Data, Cambridge, MA: MIT Press. 
Table 1. Descriptive statistics by membership status.

\begin{tabular}{|c|c|c|c|c|}
\hline & & $\begin{array}{c}\text { Stable } \\
\text { non- } \\
\text { member }\end{array}$ & $\begin{array}{c}\text { Stable } \\
\text { member }\end{array}$ & $\begin{array}{l}\text { Varying } \\
\text { member- } \\
\text { ship }\end{array}$ \\
\hline \multirow{2}{*}{ Absence days } & Mean & 15.69 & 21.55 & 18.37 \\
\hline & $\mathrm{Sd}$ & 46.84 & 53.28 & 48.48 \\
\hline \multirow{2}{*}{$\begin{array}{l}\text { Absence } \\
\text { episodes }\end{array}$} & Mean & 0.34 & 0.51 & 0.47 \\
\hline & $\mathrm{Sd}$ & 0.68 & 0.86 & 0.83 \\
\hline Any absence & Proportion & 0.25 & 0.34 & 0.32 \\
\hline$>2$ abs. episodes & Proportion & 0.07 & 0.12 & 0.10 \\
\hline$>28$ days lost & Proportion & 0.13 & 0.17 & 0.15 \\
\hline \multirow{2}{*}{ Age } & Mean & 37.14 & 42.02 & 35.45 \\
\hline & $\mathrm{Sd}$ & 11.32 & 10.21 & 10.35 \\
\hline \multirow{2}{*}{$\begin{array}{l}\text { No. of } \\
\text { employees }\end{array}$} & Mean & 64.11 & 212.11 & 112.21 \\
\hline & $\mathrm{Sd}$ & 159.56 & 338.62 & 232.00 \\
\hline \multirow{7}{*}{ Education } & $\begin{array}{l}\text { Lower sec. or } \\
\text { less }\end{array}$ & 23.9 & 20.9 & 23.5 \\
\hline & Some upper sec. & 12.1 & 14.9 & 9.1 \\
\hline & Upper sec. & 37.4 & 38.1 & 39.1 \\
\hline & Post-sec. & 4.1 & 4.0 & 3.9 \\
\hline & Bachelor level & 18.7 & 14.6 & 17.9 \\
\hline & Master level & 3.6 & 6.9 & 6.2 \\
\hline & Ph.D. level & 0.2 & 0.6 & 0.3 \\
\hline \multirow{3}{*}{$\begin{array}{l}\text { Working hours } \\
\text { per week }\end{array}$} & $<20$ & 16.1 & 6.0 & 13.9 \\
\hline & $20-29$ & 6.0 & 5.6 & 6.1 \\
\hline & $>30$ & 77.8 & 88.5 & 80.0 \\
\hline \multirow{4}{*}{ Tenure (years) } & $<1$ & 29.6 & 17.7 & 33.0 \\
\hline & 1 & 16.6 & 12.4 & 20.9 \\
\hline & $2-5$ & 30.8 & 32.7 & 32.3 \\
\hline & $>5$ & 23.0 & 37.2 & 13.8 \\
\hline \multirow{2}{*}{ Gender } & Men & 62.3 & 66.5 & 63.7 \\
\hline & Women & 37.7 & 33.5 & 36.3 \\
\hline \multicolumn{2}{|c|}{ No. of observations (person-years) } & 2543891 & 1376006 & 605736 \\
\hline \multicolumn{2}{|l|}{ No. of employees } & 818895 & 380578 & 160982 \\
\hline \multicolumn{2}{|c|}{ Mean no. of obs. per employee } & 3.11 & 3.62 & 3.76 \\
\hline
\end{tabular}


Table 2. Number of years with at least one incidence of sickness absence. Individuals observed in at least four years

\begin{tabular}{lrrr} 
& $\begin{array}{c}\text { Stable } \\
\text { non- } \\
\text { member }\end{array}$ & $\begin{array}{c}\text { Stable } \\
\text { member }\end{array}$ & $\begin{array}{c}\text { Varying } \\
\text { member- } \\
\text { ship }\end{array}$ \\
\hline 0 & 39.9 & 27.9 & 30.1 \\
1 & 28.0 & 25.4 & 27.0 \\
2 & 17.4 & 20.0 & 20.8 \\
3 & 9.5 & 14.3 & 13.4 \\
4 & 4.2 & 8.8 & 6.7 \\
5 & 1.1 & 3.7 & 2.1 \\
\hline Sum & 100 & 100 & 100 \\
$\mathrm{~N}$ & 365529 & 229022 & 98074 \\
\hline
\end{tabular}


Table 3. OLS regression of binary absence measure (at least one episode during the year) on union membership and control variables. Fixed effects for detailed industry-occupation or establishment-occupation categories. Separate analyses for employees in lower grade and higher grade occupations.

Higher grade occupations (ISCO 1-3)

Union member

Education (upper sec. omitted):

Lower sec. or less

Some upper sec.

Post-sec.

Bachelor level

Master level

Ph.D. level

Age/10

(Age/10) $)^{2}$

(Age/10) ${ }^{3}$

Days employed/100

$0.014^{* * *} \quad 0.000$

$0.023^{* * *} \quad 0.000$

$$
\text { Model } 1
$$

$\mathrm{b}$

Model 2

b se

$0.024^{* * *} \quad 0.001 \quad 0.017^{* * *} \quad 0.002$
Lower grade occupations (ISCO 4-9) Model 1 b se

$0.071^{* * *} \quad 0.001$

$0.055^{* * *} \quad 0.003$

$0.068^{* * *} \quad 0.001$

$0.020^{* * *} \quad 0.001$

$-0.016^{* * *} \quad 0.002$

$-0.060^{* * *} \quad 0.001$

$-0.096^{* * *} \quad 0.004$

$-0.027 \quad 0.030$

$-0.041^{* * *} \quad 0.001$

$-0.006^{* * *} \quad 0.000$

$0.016^{* * *} \quad 0.000$

$0.042^{* * *} \quad 0.001$

$0.064^{* * *}$

$0.023^{* * *}$

$-0.015^{* * *} \quad 0.002$

$-0.064^{* * *} \quad 0.002$

$-0.095^{* * *} \quad 0.004$

$\begin{array}{ll}-0.020 & 0.038\end{array}$

$-0.035^{* * *} \quad 0.001$

$-0.007^{* * *} \quad 0.000$

$0.015^{* * *} \quad 0.001$

$0.033^{* * *} \quad 0.001$

$0.015^{* * *} \quad 0.000$

$0.049^{* * *} \quad 0.001$

Working hours ( $>30$ hrs. omitted):

$<20$

$\begin{array}{ll}-0.050^{* * *} & 0.003 \\ -0.042^{* * *} & 0.003\end{array}$

$-0.049^{* *}$

0.004

$-0.112^{* * *}$

0.001

$-0.111^{* * *}$

0.002

$-0.042^{* * *} \quad 0.004$

$-0.056^{* * *}$

0.002

$-0.049^{* * *}$

0.002

Tenure ( $>5$ yrs. omitted):

$$
<1
$$

1

2-5

No. of employees $/ 1000$

(No. of employees/1000) ${ }^{2}$

Gender (man omitted)

Year of observation (2005 omitted):

$\begin{array}{cc}0.006^{* * *} & 0.001 \\ 0.026^{* * *} & 0.001 \\ 0.017^{* * *} & 0.001 \\ 0.039^{* * *} & 0.007 \\ -0.015^{* * *} & 0.005 \\ 0.118^{* * *} & 0.001\end{array}$

$0.006^{* * *} \quad 0.001$

$-0.010^{* * *} \quad 0.002$

$0.022^{* * *} \quad 0.001$

$0.007^{* * *} \quad 0.002$

$0.015^{* * *} \quad 0.002$

$0.043^{* * *} \quad 0.001$

$0.012^{* * *} \quad 0.002$

$0.029^{* * *} \quad 0.001$

$0.115^{* * *} \quad 0.015$

$-0.073^{* * *} \quad 0.017$

$0.122^{* * *} \quad 0.002$

$0.091^{* * *}$

0.001

$0.096^{* * *}$

0.001

$$
0.012^{* * *} \quad 0.001
$$

$0.008^{* * *} \quad 0.001$

$0.019^{* * *} \quad 0.001$

$0.019^{* * *} \quad 0.001$

2004

$-0.010^{* * *} \quad 0.001$

$-0.012^{* * *} \quad 0.001$

$-0.014^{* * *}$

0.001

$-0.014^{* * *} \quad 0.001$

2006

2007

Constant

$-0.003^{* * *} \quad 0.001$

$-0.001$

0.001

$0.002^{* * *}$

0.001

$0.004^{* * *} \quad 0.001$

$0.004^{* * *} \quad 0.001$

0.001

0.001

$0.193^{* * *} \quad 0.002$

$0.262^{* * *} \quad 0.001$

$0.005^{* * *} \quad 0.001$

$0.184^{* * *} \quad 0.002$

58284 categories

Industry-occupation

Establishment-occupation

$\mathrm{R}^{2}$ (within)

0.033

0.092

Note: Age is centred at 40 years, and number of employees at 80 . Sig

$\mathrm{N}$

$\mathrm{R}^{2}$ (including fixed eff.)
280547 categories

0.031

0.270

1493141
46554 categories

323307 categories

0.036

0.199

2900337 $\mathrm{p}<.10$.

0.039
0.075
2900186

$0.274^{* * *} \quad 0.002$ 
Table 4. Relative level of sickness absence for union members compared to non-members under different specifications.Within industry-occupation (Model 1) and within establishment-occupation (Model 2) estimates.

\begin{tabular}{|c|c|c|c|c|c|c|c|c|}
\hline & \multicolumn{4}{|c|}{ Higher grade occupations } & \multicolumn{4}{|c|}{ Lower grade occupations } \\
\hline & \multicolumn{2}{|c|}{ Model 1} & \multicolumn{2}{|c|}{ Model 2} & \multicolumn{2}{|c|}{ Model 1} & \multicolumn{2}{|c|}{ Model 2} \\
\hline & $\mathrm{RR}$ or & & $\mathrm{RR}$ or & & $\mathrm{RR}$ or & & RR or & \\
\hline & IRR & se & IRR & se & IRR & $\mathrm{se}$ & IRR & se \\
\hline OLS (from Table 2) & 1.112 & 0.006 & 1.078 & 0.008 & 1.244 & 0.004 & 1.190 & 0.005 \\
\hline Poisson, no. of episodes & 1.134 & 0.007 & 1.096 & 0.008 & 1.308 & 0.009 & 1.224 & 0.005 \\
\hline Poisson, no. of days lost & 1.089 & 0.010 & 1.084 & 0.012 & 1.200 & 0.008 & 1.158 & 0.007 \\
\hline OLS, $>1 \mathrm{v} . \leq 1$ episodes & 1.196 & 0.013 & 1.151 & 0.018 & 1.466 & 0.010 & 1.365 & 0.011 \\
\hline OLS,$>28$ days lost $\mathrm{v} . \leq 28$ & 1.103 & 0.008 & 1.088 & 0.011 & 1.254 & 0.006 & 1.211 & 0.007 \\
\hline
\end{tabular}

Note: RR's are computed for OLS models as the average marginal probability of sickness absence for union members divided by the same statistic for non-members. IRR's are exponentiated coefficients from Poisson regressions, which can be interpreted as the relative rate of sickness absence among union members compared to that of non-members. All RR's and IRR's are significantly different from one at the .01 level 
Table 5. Relative level of sickness absence for union members compared to non-members under different specifications. Within industry-occupation (Model 1) and within industry-occupationindividual (Model 2) estimates.

OLS, any absence v. no absence

Higher grade occupations Lower grade occupations

OLS, $\geq 2$ v. $<2$ episodes

\begin{tabular}{rrrrrrrr}
\multicolumn{2}{c}{ Model 1 } & \multicolumn{2}{c}{ Model 2 } & \multicolumn{2}{c}{ Model 1 } & \multicolumn{2}{c}{ Model 2 } \\
RR & se & RR & se & RR & se & RR & se \\
1.120 & 0.007 & 1.076 & 0.012 & 1.249 & 0.007 & 1.123 & 0.007 \\
1.210 & 0.016 & 1.166 & 0.032 & 1.476 & 0.016 & 1.239 & 0.015 \\
1.116 & 0.010 & 1.120 & 0.020 & 1.257 & 0.011 & 1.202 & 0.011
\end{tabular}

OLS, $>28$ days lost $\mathrm{v} . \leq 28$

$\begin{array}{lllllllll}1.116 & 0.010 & 1.120 & 0.020 & 1.257 & 0.011 & 1.202 & 0.011\end{array}$

Note: See note to Table 4 
Figure 1. Average marginal probabilities of sickness absence as a function of union membership and union density for lower grade and higher grade occupations

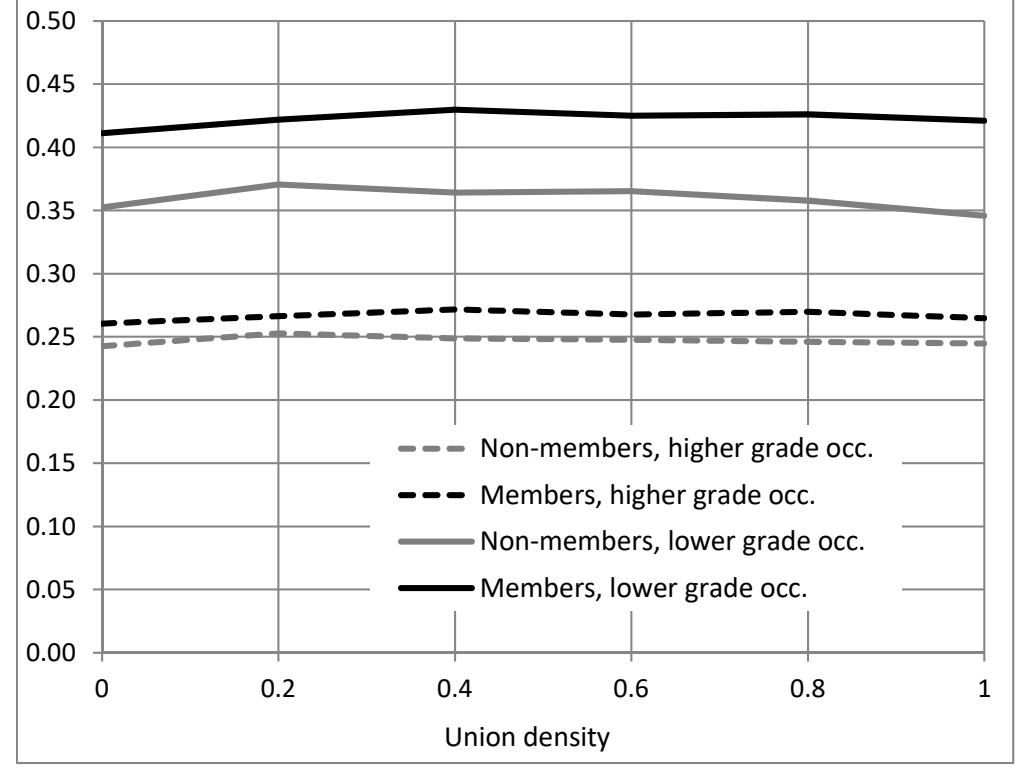


Figure 2. Effects on sickness absence associated with the years preceeding and succeeding termination of union membership

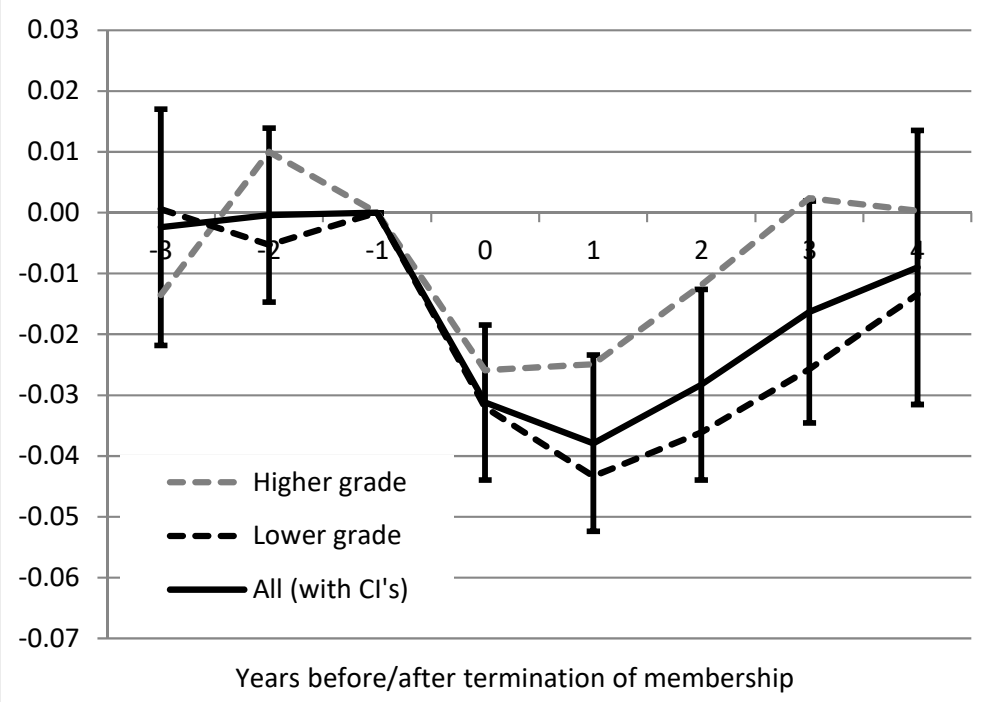

Note: Coefficients and $95 \%$ confidence intervals based on estimation of Eq. (3). The year before the termination is used as reference 


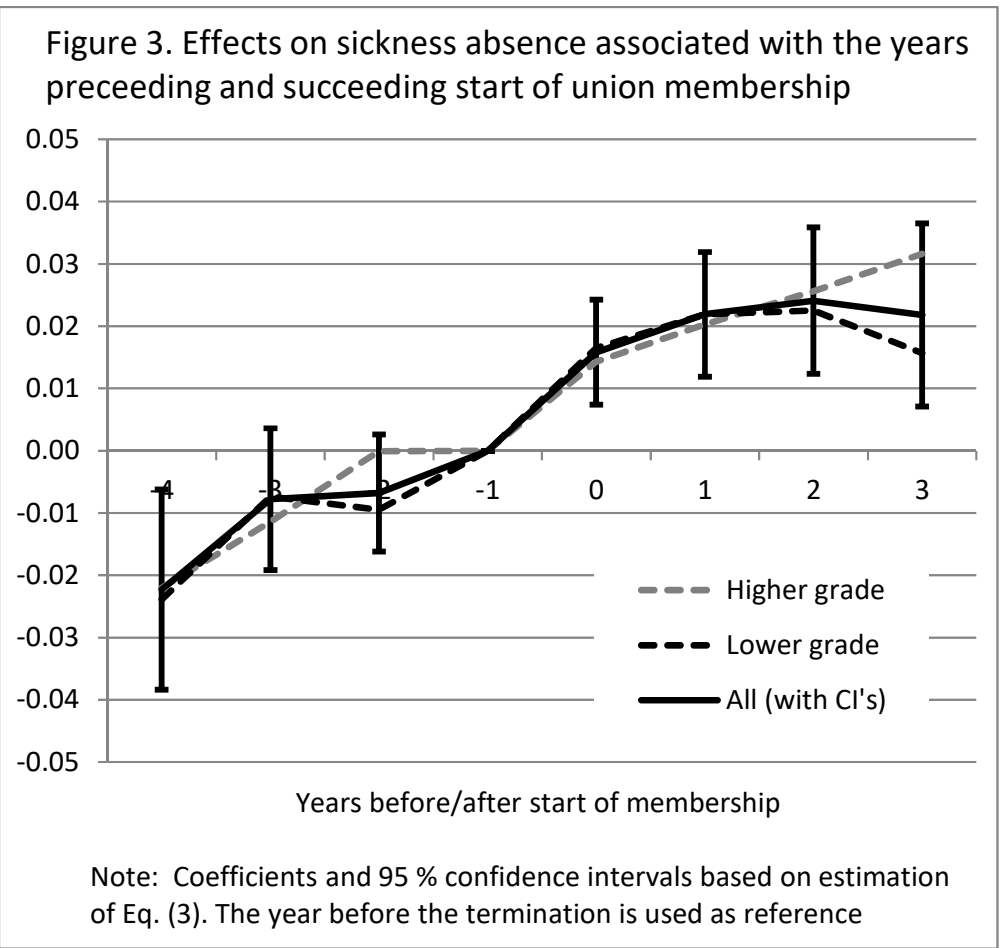

